\title{
The case for prison depopulation: Prison health, public safety and the pandemic
}

\author{
Howard Sapers*
}

Recently, I have been hearing about two related questions: Why is it important to implement accelerated release from custody as part of the response to COVID-19, and will public safety be jeopardized as a result?

The profile of those in custody suggests a vulnerable, high-needs population. Pre-existing physical and mental health issues, history of substance abuse, history of sexual and physical abuse, low educational attainment, chronic under- or unemployment, unstable housing, and social relationships are typical. The demographics are also troubling. In Canada's federal prisons, $25 \%$ of the population is serving an indeterminate (life) sentence and a growing proportion of all prisoners are aged over 50 (now more than 1 in 4). While the 2016 census found $4.9 \%$ of Canadians self-identified as Indigenous and 3.5\% as Black, 30\% of all prisoners are Indigenous (this grows to over $40 \%$ for women), and $8 \%$ are Black. The over-representation in prison of Indigenous and Black Canadians, as well as those with histories of substance misuse and mental illness and those who are aging and dying, is a long-standing trend. The needs they have for support, care, and safety do not fade away during a public health emergency.

In 2015, the Canadian Medical Association published an article by Lynn Stewart, a Senior Research Manager at Correctional Service Canada (CSC), that included the following observations:

There is reason to be concerned that rates of chronic health conditions of federal inmates may be increasing because of demographic shifts in the incarcerated population. For example, the proportion of incoming offenders aged 50 years or older has grown over the last 10 years, from $7.5 \%$ in 2003/04 to $13.3 \%$ in 2012/13. Among incarcerated offenders in 2012/13, 21.5\% were 50 years or older. Older inmates generally require more healthcare services than younger inmates because they are more likely to have chronic diseases and disabilities and consequently have more specialized needs for care and assistance with mobility and daily living. Despite the increase in the proportion of older inmates, the overall inmate population is younger than the general Canadian population: based on the latest census, $15 \%$ of the general population is 65 years and older, as compared with $3.5 \%$ of federal inmates.
Another factor that could affect the overall prevalence of health conditions among federal inmates is the increased proportion of inmates who are of selfreported Aboriginal ancestry. From 2003/04 to 2012/13, the Aboriginal federal inmate population increased by $47.2 \%$, and in $2012 / 13,23 \%$ of federal inmates were of self-reported Aboriginal ancestry. Overall, Aboriginal populations in Canada face a higher prevalence of health conditions and a lower life expectancy than the nonAboriginal population. Evidence suggests that many of the health conditions seen in the general population of Aboriginal Canadians (e.g., diabetes, obesity, and drug and alcohol abuse) are more prevalent in Aboriginal inmate populations. Other areas that affect the relatively lower life expectancy of Aboriginal inmates are the higher rates of suicide and injury from violence. (Stewart et al., 2015)

COVID-19 is an infectious disease that can easily spread amongst people in close contact. Infection comes either through exposure to droplets produced by coughing, sneezing, or talking, or as a result of touching surfaces contaminated by the droplets. Onset of illness is reported to occur within 2 to 14 days of exposure, and severity of symptoms can quickly escalate. People with underlying or pre-existing conditions related to their immune or respiratory systems appear to be the most vulnerable to this disease. There are no vaccines or proven antivirals currently available. COVID-19 can be deadly. The U.S.-based Prison Policy Initiative has stated. "Prisons and jails are amplifiers of infectious diseases such as COVID-19, because the conditions that can keep diseases from spreading — such as social distancing - are nearly impossible to achieve in correctional facilities." (PrisonPolicy.Org, 2020)

Conclusions concerning the health status of prisoners in Canada (Kouyoumdjian, Schuler, Matheson, \& Hwang, 2016) included the following:

Canadians in correctional facilities have poor health across a range of health status indicators, a finding that is consistent with international data on persons who experience imprisonment. This information is relevant to physicians who assess and treat persons while in custody

Correspondence to: Howard Sapers, Department of Criminology, University of Ottawa, 120 University Private, Ottawa, ON K1N 6N5. E-mail: Howard.Sapers@gmail.com To cite: Sapers, H. (2020). The case for prison depopulation: Prison health, public safety and the pandemic. Journal of Community Safety and Well-Being, 5(2), xxx-xxx. https://doi.org/10.35502/jcswb.136

@ Author(s) 2020. Open Access. This work is distributed under the Creative Commons BY-NC-ND license. For commercial re-use, please contact sales@sgpublishing.ca. gPUBLISHING Published by SG Publishing Inc. CSRA Official publication of the Community Safety Knowledge Alliance. 
or after release, as it might inform history taking, counselling regarding pre-test probability, investigations, and management strategies.

Information on health status is also important for defining areas of focus for improving health and healthcare. Healthcare in correctional facilities is largely delivered by government authorities in Canada, which makes the lack of data on some key indicators of health striking, including on mortality after release, chronic diseases, injury, and healthcare access and quality. Among other measures, the implementation of electronic medical records, which are still not available in correctional facilities in many jurisdictions, could facilitate the collection and management of data on many health status indicators.

Taken together, prisoner demographics (an aging population with generally poorer health than people outside of prison, a high proportion of vulnerable and marginalized populations heavily negatively impacted by the social determinants of health, a high prevalence of substance misuse and mental health issues), security-driven infrastructure not well suited to providing health promotion, prevention, and treatment, challenges in recruiting and retaining health professionals, and a lack of data and analysis to help shape healthcare strategies, planning, and provision make Canada's jails and prisons dangerous places for those in custody during this pandemic.

Too many structural and operational barriers must be overcome before current levels of incarceration can be safely maintained. The dual purpose of prisons is to protect the public and prepare those who are incarcerated for safe and timely return to the community. Both goals are undermined by the pandemic. Public safety and public health both suffer when prison conditions threaten the health and well-being of those in custody and those who are responsible for their care.

Correctional services around the globe have been adapting to the pandemic. Most are changing policy and practice, while some jurisdictions have altered corrections legislation and regulation. The intent is to decrease the number of people in custody and reduce the likelihood of infection for those who remain.

A recent article published in The Lancet provides a sobering international overview (Burki, 2020). Unsafe, unsanitary, and crowded conditions of confinement, inadequate access to health services, poor nutrition, and a health-compromised prisoner population characterize the jurisdiction reviewed in the article. The key conclusion is that decarceration is the "only answer" to meeting the threat of COVID-19 and that several jurisdictions have in fact prioritized release as their response (Burki, 2020).

On April 28, 2020, the Prison Policy initiative reported 49 separate local, county, and state initiatives reducing custody populations in response to COVID-19 (PrisonPolicy.Org 2020). These include a $44 \%$ drop in the Hennepin County, Minnesota, jail population and a $41 \%$ decrease in Denver, Colorado, following the release of those over 60 , those who are pregnant, those with health vulnerabilities and those with less than 60 days remaining in their sentence. Dallas County, Texas, released 1,000 prisoners to help reduce transmission, and Los Angles County Sheriff's Department is releasing people with less than 30 days remaining on their sentences.
Some U.S. jurisdictions are taking proactive measures, others are responding to court orders. Some state governors (including Tom Wolf in Pennsylvania, Jay Inslee in Washington, and Phil Murphy in New Jersey) have signed executive orders to facilitate the early release of sentenced, non-violent prisoners. The press release announcing the Washington State initiative is explicit that the purpose of accelerated release is to affect physical distancing:

The Washington State Department of Corrections is planning for the transfer of incarcerated individuals back to their communities. The goal in transferring a limited number of individuals to the community is to provide more physical distancing within the state's correctional facilities. (Department of Corrections, Washington State 2020)

The issues and challenges driving concern and action internationally are not dissimilar to the those faced in Canada. Canadian jurisdictions have implemented initiatives to both reduce intake and to mitigate health risks. Common elements of the response to COVID-19 by correctional services across the country include enhanced personal protection measures for staff that follow general public health advice, provision of written infection management information to employees, provision of personal protective equipment, and screening and temperature checking of people entering facilities. Movement in and out of, as well as within, correctional facilities has been significantly restricted. Programs, activities, and other forms of association have been cancelled or curtailed. Inperson visits are almost uniformly forbidden, and telephone and video contact has been enhanced. Testing of prisoners with flu-like symptoms is commonplace.

Between March 12, 2020, and April 15, 2020, Ontario reduced its custody population by $29 \%$. This was achieved through regulatory changes and collaborative efforts between ministries, police, and other agencies to increase the use of video court appearances, encourage the use of non-custodial sentences, permit longer-term temporary absences, conduct remote parole hearings and reduce the number of bail hearings. Ontario Corrections now proactively performs a temporary absence review for all prisoners with less than 30 days remaining on their sentence and is granting temporary absences to those serving intermittent sentences (Ministry of the Solicitor General, 2020).

British Columbia released nearly $6 \%$ of its in-custody population between March 1, 2020, and April 1, 2020. Most of those released were serving intermittent sentences. Their release followed individual risk assessments prompted by a desire to reduce the potential for an outbreak within the province's jails. Pre-trial intake has also declined, further reducing the in-custody population. B.C. Corrections has initiated daily pandemic planning meetings within all its jails.

Manitoba has used Unescorted Temporary Absences to reduce its custody population and to allow those sentenced to intermittent incarceration to serve their sentences at home. The "count" as of April 27, 2020, was 1,638, down from an average daily "count" of 2,144 during the fiscal year ending March 31, 2020.

As of April 22, 2020, Nova Scotia had reduced its custody population by nearly 50\% (from 452 to 251). Temporary absences for those serving intermittent sentences and those 
within 30 days of their sentence ending, public health-focused case reviews and the use of video bail hearings on weekends and over Easter contributed to the reduction. Between March 1, 2020, and March 23, 2020, Newfoundland and Labrador released 17 prisoners from custody who were within 30 days of the end of their sentence. An increase in bail hearings has led to a reduction of the remand population.

Clearly, provincial and territorial governments are aware of the risks to the health of custodial populations during a pandemic and are engaged in mitigation initiatives. While some jurisdictions are reporting few or no cases of COVID-19, all are taking preventive measures, including early release. The use of temporary absences, identification of at-risk individuals, enhanced case work and assessment and working with community partners have contributed to reduced custody populations and a decrease in the potential spread of disease.

Concerns have been expressed that early release initiatives will compromise public safety. There is no evidence to support this concern. There is evidence that incarceration rates and crime rates are predominately independent of each other. As Andrew Coyle, the founder of the International Center for Prison Studies, has said:

We can safely say that the difference in rates of imprisonment between the United States and neighbouring Canada, between England \& Wales and Germany, between New Zealand and Australia and between the other countries which I have mentioned cannot be explained by differences in levels of crime. (Coyle, 2011)

A brief prepared for the Prison Policy Initiative documented 14 examples of large-scale decarceration in the United States, Finland, Czech Republic, Israel, Italy, and Russia (Wagner, 2020). What all these examples share is no documented increase in crime rates or seriousness.

A Canadian example of safe decarceration took place in Alberta between 1993 and 1997. During that period, Alberta saw its use of incarceration drop by $32 \%$ (Webster \& Doob, 2014). This drop was not because of a sudden decrease in arrests, charges, or prosecutions, but the result of fiscal policy driving all provincial government departments to cut budgets and reduce spending. Once again, there is no evidence of a crime wave following the decarceration.

Parole success rates in Canada are high. The successful completion rate for federal day parole releases in 2017-2018 was $92.2 \%$. Most day parole breaches result from violation of conditions of release, not new crimes. Over the last five years, the rate of violent re-offending for federal prisoners released on day parole averaged $0.1 \%$. The success rate for federal prisoners released on full parole has increased to $90.5 \%$, while the rate of violent re-offending for those in the community on full parole has been decreasing over the last five years, averaging $0.5 \%$ (Public Safety Canada Portfolio Corrections Statistics Committee, 2018).

The topic of a January 2020 gathering of justice sector leaders in Montreal was Alternatives to Short-Term Custody. Deliberations were informed by presentations from Scotland, Denmark, and Norway-jurisdictions that have made efforts to reduce or eliminate short-term sentences to custody. The common theme that emerged was that short sentences are not effective deterrents and may in fact contribute to criminality. The clear policy implications are that Canada should avoid short periods of incarceration and pay rigorous attention to the principle of restraint that requires incarceration to be used as a last resort.

When people are sentenced to prison, they are not sentenced to further punishment that may arise from the circumstances of imprisonment. Correctional services are not supposed to add to the sentence of the court through unreasonably harsh, punitive, or dangerous conditions of confinement. The threat of COVID-19 in prison poses a grave risk to health. Death can come suddenly after exposure, particularly if health treatment is not immediately available. I believe this is above and beyond what could be considered as the inherent pains of imprisonment, and that accelerated release will save lives without compromising public safety.

CONFLICT OF INTEREST DISCLOSURES

The author declares there are no conflicts of interest.

AUTHOR AFFILIATIONS

*Visiting Professor, University of Ottawa, Department of Criminology, Former Correctional Investigator of Canada, Ottawa, ON.

\section{REFERENCES}

Burki, T. (2020). Prisons are "in no way equipped" to deal with COVID-19. The Lancet, 395(10234), 1411-1412. doi: 10.1016/S0140-6736(20)30984-3

Coyle, Andrew. (2011, May). A human rights approach to prison management. Presented at the European Federation of Public Service Unions Conference. Conference conducted at the International Centre for Prison Studies, Athens, Greece.

Department of Corrections Washington State. (2020, April 16). Corrections announces upcoming transfer of individuals back to the community. [Press Release]. Retrieved from https://doc. wa.gov/news/2020/04162020p.htm.

Kouyoumdiian, F., Schuler, A., Matheson, F. I., \& Hwang, S. W. (2016). Health status of prisoners in Canada. Canadian Family Physician, 62(3), 215-222.

Ministry of the Solicitor General. (2020, March 20). Ontario stepping up measures to limit the spread of COVID-19 in correctional system. [Press Release]. Retrieved from https://news.ontario.ca/ mcscs/en/2020/03/ontario-stepping-up-measures-to-limit-thespread-of-covid-19-in-correctional-system.html.

PrisonPolicy.Org. (2020) Responses to the COVID-19 Pandemic. Retrieved from www.prisonpolicy.org/virusresponse.html\#tresources

Public Safety Canada Portfolio Corrections Statistics Committee. (2018). 2018 corrections and conditional release statistical overview. (Report Cat. No.: PS1-3EPDF). Ottawa: Public Works and Government Services Canada.

Stewart, L. A., Nolan, A., Sapers, J., Power, J., Panaro, L., \& Smith, J. (2015). Chronic health conditions reported by male inmates newly admitted to Canadian federal penitentiaries. CMAJ Open, 3(1), E97-E102. doi: 10.9778/cmajo.20140025

Wagner, P. (2020, April 9). Large scale releases and public safety. [Brief]. Retrieved from https://www. prisonpolicy.org/ blog/2020/04/09/large-scale-releases/.

Webster, C. M., \& Doob, A. N. (2014). Penal reform "Canadian style": Fiscal responsibility and decarceration in Alberta, Canada. Punishment \& Society, 16(1), 3-31. doi: $10.1177 / 1462474513506272$ 